Maria Irene Ramalho*

Universidade de Coimbra

\title{
Eukié: Maria Velho da Costa e o absurdo ${ }^{1}$
}

Resumo:

Este trabalho é uma primeira abordagem da ficção de Maria Velho da Costa à luz do nonsense de Lewis Carroll. Aqui se mostra que os livros de Alice de Lewis Carroll desempenharam um papel importante na construção da imaginação poética de Maria Velho da Costa. Em The Story of Alice de Robert Douglas-Fairhurst, aprendemos que Lewis Carroll usou o nonsense e o absurdo obliquamente, por vezes talvez sem se dar conta, para pintar as contradições da sociedade vitoriana, como se de uma fábula se tratasse. Maria Velho da Costa, por sua vez, usa deliberadamente o nonsense e o absurdo para denunciar as gritantes e injustas desigualdades da sociedade portuguesa, ao mesmo tempo que caricatura implacavelmente as persistentes pretensões e o potencial para a corrupção das suas classes dirigentes, no Portugal de antes e depois do 25 de Abril.

Palavras-chave:

Maria Velho da Costa, Lewis Carroll, língua, o absurdo

Abstract:

This article is a first approach to Maria Velho da Costa's art of fiction in the light of Lewis Carroll's nonsense and is mainly concerned with poetic language as social and cultural criticism.

Keywords:

Maria Velho da Costa, Lewis Carroll, language, the absurd

Aprender o absurdo. A coisa mais natural.

O livro do meio, 386

Em entrevista conduzida por Tiago Bartolomeu Costa em 2013, Maria Velho da Costa fala de autores que admira ou que foram importantes na sua formação literária, com destaque para Camões (que a autora diz ter numa cadeira junto à cama, e a quem reza regularmente). No entanto, não se lhe ouve nunca falar de "influência", palavra, de resto, que também eu procuro sempre evitar nos meus ensaios críticos. ${ }^{2}$ Prefiro lembrar a definição que de poeta de si deu um dia António Ramos Rosa: "como poeta [...] sou um leitor de poesia" (2002: 233-234). 
Cadernos de Literatura Comparada

Eukié: Maria Velho da Costa e o absurdo

Poetas (palavra que uso sempre no sentido mais lato do termo) não são senão leitores. E quem lê Maria Velho da Costa sabe disso muito bem. Uma leitora que tira prazer em tresler e reduzir ao absurdo, um absurdo aprendido logo na escola: "um dó li tá" a ritmar o jogo da corda (como ela lembra em O livro do meio) (Carvalho/Costa 2006: 386). É sobre o absurdo em Maria Velho da Costa que escrevo aqui, passando por Lewis Carroll, nome, tanto quanto sei, nunca mencionado pela autora em entrevistas.

Logo no início de Maina Mendes, o romance, diz-se que Maina Mendes, a personagem, tem o maior respeito pelo "direito ao absurdo", seja o seu ou o de qualquer outra pessoa (Costa 1969: 26). Vale a pena revisitar a cena, que faz lembrar um rito de iniciação. Maina Mendes, que, no capítulo anterior, tinha acabado de aprender um gesto obsceno de um rapazito que ela observara na rua da janela do quarto, está agora na cozinha com a criada Hortelinda. É evidente que a criança tira enorme prazer da cena doméstica em que Hortelinda vai suando e resmungando sobre os pratos complicados que lhe mandaram fazer. A narrativa subtil faz sobressair o contraste entre o mundo dos patrões e o mundo dos servos, um contraste de que a jovem Maina Mendes começa a dar-se conta. A menina, bem consciente da sua transgressão, tira enorme prazer das imagens vibrantes, cheiros fortes, sabores picantes e sons vernáculos do mundo de Hortelinda, que contrastam fortemente com a fria lassidão adocicada e repressiva do mundo em que a mãe pretende educá-la. De particular importância na educação popular de Maina Mendes contam-se os provérbios e as canções tradicionais portuguesas a que constantemente recorre Hortelinda para disfarçar a impotência na sua sofrida condição de oprimida. Por exemplo, o provérbio "Albarde-se o burro à vontade do dono" vai-lhe dando ânimo para realizar as tarefas mais árduas. $\mathrm{O}$ mesmo se diga dos trocadilhos e versos disparatados mas decididamente escatológicos sobre um pároco malandro e o que ele faz às suas ditas "irmãs" na sacristia. Maina Mendes adora repetir os sons absurdos que sabe são proibitivamente grosseiros, já que Hortelinda, se bem que exibindo neles o maior gozo, procura escondê-los da patroa. É neste contexto - dois mundos tão próximos e tão absurdamente distantes - que Maina Mendes aprende a respeitar o absurdo: "Por toda a vida Maina Mendes sagraria assim, dessa crua distância, o direito ao absurdo dos demais e seu."

Tal como a sua primeira protagonista de relevo, Maria Velho da Costa alimenta-se de absurdo, jogando com aparentes desconchavos, contra-sensos e paradoxos. Sugiro que o modo como a romancista lida com o absurdo tem muitas afinidades com o nonsense sério, ou nonsense-com-sentido, de Lewis Carroll. Um crítico caracterizou um dia os chamados Alice books [os livros de Alice] (doravante, Alice) como "the most enchanting nonsense in the English language" [o nonsense mais cativante em língua inglesa]. ${ }^{3}$ Eu prefiro chamar-lhe nonsense sério, ou, como opina a Mock Turtle em Alice's Adventures in Wonderland, uncommon sense [sentido incomum ].4 Desocultar o poder da língua de dizer e desdizer ao mesmo tempo, de nos falar e falar por nós fazendo-nos crer que somos nós quem fala, ou, como desabafou em 0 mapa cor-de-rosa, com assombro, Maria Velho da Costa, uma escritora escrupulosamente atenta à sua arte: "Como se fôssemos nós que nos escrevêssemos" (Costa 1984: 141).

Referi-me já, em trabalhos anteriores, às muitas alusões a Alice em vários romances de 
Maria Velho da Costa. ${ }^{5}$ Em Maina Mendes, publicado em 1969, não se encontra nenhuma alusão explícita. No entanto, o romance conta a história de uma jovem mulher que sobrevive num mundo de absurdidades, algumas de responsabilidade sua, e que desiste de falar "para não ser incomodada", como explica uma personagem-escritora em um romance posterior. ${ }^{6}$ Em Myra (2008), outra história de uma jovem rodeada de absurdidades, algumas das quais igualmente de sua própria responsabilidade, encontram-se não só referências explícitas mas também alusões oblíquas a Alice, tais como significativos trocadilhos ou distorções linguísticas com efeitos paródicos, ou animais comicamente comentando as acções aparentemente absurdas dos seus donos humanos. Vale a pena comparar (e contrastar) a heroína epónima de Myra com a heroína epónima de Maina Mendes: se a principal arma de Maina Mendes para a sua sobrevivência é a mudez, a de Myra é a sua verve feroz. Como se, e parafraseio aqui a autora em outro lugar, "toda, toda a escrita [fosse] compensatória de um silêncio" (cf. Costa 1984: 16).

Não admira que o uso que Maria Velho da Costa faz da língua nos lembre Lewis Carroll. Tal como ele, ela é exímia em reinventar a língua nos seus limites mais disparatados e paradoxais. Escrevo isto tendo em mente as reflexões filosóficas de Gilles Deleuze sobre sentido, sem-sentido, nonsense e paradoxo em Logique du sens (1969). As reflexões de Deleuze são largamente inspiradas nas obras de Lewis Carroll, tanto a ficção de Carroll como a ciência de Charles L. Dodgson, se bem que a ficção pareça estimular a imaginação filosófica de Deleuze muito mais produtivamente do que a ciência. Tal como tantos outros filósofos, também Deleuze encontra nos poetas o solo mais fértil para as suas reflexões filosóficas, em particular no que diz respeito à complexidade da língua. Et pour cause. Pois não são os poetas os mais exímios desconstrutores, desmistificadores e desmitificadores da língua? Em Logique du sens, como de resto em toda a obra de Deleuze, com ou sem Guattari, são os poetas que fornecem à filosofia o sentido mais apurado dos contra-sensos e paradoxos da língua, da complexidade dos nomes, do nomear, re-nomear e chamar pelo nome. Valéry, Mallarmé, Borges, entre outros, além de Lewis Carroll, dão sentido à Lógica do sentido de Deleuze. Neste livro, Deleuze explora muitas formas de paradoxo na tradição filosófica ocidental, incluindo um paradoxo que designa por "paradoxo de Lewis Carroll" (Deleuze 1969: 41-43). É o paradoxo da regressão, ou da proliferação indefinida ("paradox de la régression ou de la prolifération indéfinie"), tal como Deleuze a entende, por exemplo, na actuação do White Knight no VIII capítulo de Through the Looking Glass and what Alice Found There. O Cavaleiro Branco diz a Alice o nome de uma canção que ele está prestes a cantar-lhe, servindo-se de uma absurda proliferação de nomes, revelando o que cada sucessivo nome é chamado e explicando o que chamar nomes à coisa faz ao sentido da coisa. Neste caso, a coisa é a canção de despedida do Cavaleiro Branco dedicada a Alice. Vêm à ideia os muitos nomes diferentes que a heroína epónima de Myra se vai chamando, e ao seu cão. Só quando o seu amado, Orlando, está a morrer lhe diz ela que o seu verdadeiro nome é Myra, e o do cão, Rambo/Rimbaud. Curioso e irónico, na auto-intertextualidade dos romances de Maria Velho da Costa, é que a "proliferação de nomes" já tinha sido usada pelo próprio Orlando (que aliás é também Rolando) em Irene ou o contrato social (Costa 2000: 111ss). 
Para os meus propósitos aqui, o exemplo de paradoxo mais simples, e mais relevante, é o jogo de palavras, ou trocadilho: é um paradoxo porque a sonoridade da palavra produz mais do que um sentido ao mesmo tempo e não deixa que se descarte nenhum deles. Ambos, ou todos, fazem sentido, o que pode ser terrivelmente confuso. O capítulo X é particularmente fértil, por exemplo, com uma pescadinha (whiting) que é brancura (white) e um golfinho (porpoise) que é também um objectivo (purpose). Mais interessante ainda é observar uma estupefacta Alice a escutar a longa e triste história (tale) do rato no III capítulo de Alice's Adventures in Wonderland como uma longa e serpenteante cauda (tail). A intrigante absurdidade do episódio resulta do jogo da homofonia de tale (história) e tail (rabo [do rato]). No mesmo episódio, a confusão que Alice faz entre not (não) e knot (nó) recorda-nos que a poesia é sound reasoning, ou seja, som-que-faz-sentido, tal como nos ensina o poeta inglês do século XVIII Christopher Smart (1966: 106-108). Ou, atrevo-me a dizer, som-sem-sentido-que-faz-sentido ("um dó li tá" e o saltitante jogo da corda em 0 livro do meio). A certa altura, durante o diálogo enlouquecedor entre Alice e a Duquesa no IX capítulo de Alice's Adventures in Wonderland, uma das "moralidades" (morals) da Duquesa é realmente uma paródia de um provérbio inglês: "Take care of the sense, and the sounds will take care of themselves" [Cuidai do sentido e os sons cuidarão de si próprios].7 Uma tal paródia, observa Deleuze, não deixa de sugerir uma ligação estreita entre "a lógica do sentido e a ética, a moral ou a moralidade" (Deleuze 1969: 44); mas o que o filósofo não chega a observar é a ligação lógica com a poesia enquanto sound reasoning (raciocínio sonoro-com-sentido). Por isso, a minha paródia do provérbio inglês - "Take care of the pence and the pounds will take care of themselves" [Cuidai dos pence e as libras tomarão conta de si] - diria antes "cuidai dos sons e o sentido tomará conta de si".

Abundam em Maria Velho da Costa reescritas paródicas ou traduções deliberadamente atamancadas de provérbios, nomes e títulos famosos ou versos bem conhecidos, por vezes em inesperadas combinatórias. Trocadilhos e jogos de palavras absurdos sublinham sem dó nem piedade as muitas absurdidades da cultura em geral. Um exemplo particularmente impudente em Casas Pardas é quando a aspirante a escritora, Elisa, escuta os sons trémulos e melodiosos do conjunto The Platters em "Only You" e, como se em busca da expressão adequada, "traduz" Shakespeare numa "pera tremente": "[...] as coisas que Eu já vi e não sei dizer, tios Guilhermes, shakes pear, pera tremente e tel quel, do platter [...]" (Costa 1986: 65). Noutro momento na Casa de Elisa, o "Tio Guilherme" é "(The Shakes)" (idem: 161). A "tradução" insolente será mais tarde repetida de novo em Irene ou o contrato social (Costa 2000: 164), homenagem perfeita ao príncipe da língua inglesa, mestre supremo do trocadilho e um dos autores que mais povoam a obra de Maria Velho da Costa. ${ }^{8}$ São os sons da língua que constroem o sentido da realidade nos sons do poema-enquanto-heterocosmo, como nos ensinou M. H. Abrams há já tantos anos. ${ }^{9}$ Jogando com o abismo entre a palavra e a coisa, a poesia problematiza aquilo que normalmente designamos por comunicação linguística, e põe em causa a referência, por vezes de forma tão radical como o nonsense não-referencial do "Jabberwocky" de Lewis Carroll.

Tal como Lewis Carroll, ou talvez, acrescentaria eu, tal como qualquer grande poeta, Maria Velho da Costa, que tem firmemente negado jamais ter escrito poesia (quer ela dizer, versos), ${ }^{10}$ 
depende da polissemia e opacidade da língua para as suas criações mais imaginativas e subversivas. Vejamos como ela medita sobre a palavra "cravo", a flor vermelha que é símbolo da Revolução de 25 de Abril de 1974, em que não houve derramamento de sangue. Numa breve introdução à colectânea que tem este título (Cravo), Velho da Costa explica que nem sequer gosta da flor, que lhe parece demasiado fálica e agressiva. Ao mesmo tempo, no entanto, revela um grande fascínio por todos os sentidos e sensações que a palavra "cravo" evoca: a bela flor vermelha, claro está, mas também o prego acerado, a inestética verruga, o instrumento musical e a especiaria (cravo-da-Índia ou cravinho) (Costa 1976: 11-13). Cravo foi publicado em 1976: que sentidos contraditórios e potencialmente absurdos nos convida Maria Velho da Costa a ouvir na icónica expressão "A Revolução dos Cravos" dois anos apenas depois da Revolução de Abril? Como não pensar nas perplexidades linguísticas de Alice, que encorajam a leitora a perguntar pela cultura em geral? Como sugerem, por exemplo, os sentidos confusos de well [o substantivo "poço" e o advérbio "bem"] e draw ["extrair" e "desenhar"] na história de melaço (treacle) contada pelo sonolento arganaz no VII capítulo de Alice’s Adventures in Wonderland.

Longe de mim falar de "influência", conceito de que devia precaver-se quem quer que escreva sobre poesia (no sentido mais amplo e rigoroso do termo, como sempre nos meus trabalhos críticos). Prefiro falar de constelações de poetas. A literatura (que é como quem diz, a poesia) escreve-se na literatura, ou na poesia. Toda a obra de Maria Velho da Costa, que eu não hesito em classificar como uma grande poeta (o termo de Harold Bloom que tenho em mente é $a$ strong poet), está salpicada de alusões a literatura em muitas línguas diferentes e de diferentes culturas. Em geral, a autora põe em itálico as alusões que não identifica. Em Myra, por exemplo, "um tigre a arder" (Costa 2008: 173) claramente evoca "tyger burning bright" do famoso poema de William Blake, cuja "temível simetria" fora antes invocada em Casas pardas ("Tua temível simetria" [Costa 1986: 301]). ${ }^{11}$ Mais relevante no contexto deste meu trabalho, em Irene ou o contrato social, Orlando, ao despedir-se um dia da irmã, invoca a pressa do Coelho Branco de Alice dizendo, I'm late, I'm late, for a very important date (Costa 2000: 49), expressão que, de resto, vem directamente do filme de Disney de 1951, Alice in Wonderland.

Nas epígrafes que escolhe, Velho da Costa deixa as alusões bem explícitas. As epígrafes são elos da grande cadeia do pacto entre a autora e quem a lê..$^{12} \mathrm{O}$ primeiro livro de escrita criativa de Maria Velho da Costa, O lugar comum (1966), abre com uma epígrafe do escritor senegalês, Cheikh Hamidou Kane. É uma de duas epígrafes que ela usa nesta colectânea de contos. O título do primeiro conto, a que está associada a epígrafe retirada de Kane, "Exílio Menor", convoca obliquamente o exílio doloroso narrado no romance pós-colonial de Cheikh Kane, L'aventure ambiguë (1961), ao qual Maria Velho da Costa de novo alude em Casas Pardas e Myra. ${ }^{13} \mathrm{~A}$ importância da segunda epígrafe para o conto a que preside é mais misteriosa, a raiar o paradoxal. Apresenta-se como o "Hino ao Sol", que se diz ter sido escrito pelo Faraó egípcio, Amenophis (ou Akhenaten), sendo que o sol é o deus Aton, origem de toda a vida. No entanto, o conto intitula-se "A velada" e o poema, identificado como "Amenophis IV, Hino Solar", não fala senão das negras sombras da morte. E muito bem, em vista da narrativa que se segue, a 
Cadernos de Literatura Comparada

Eukié: Maria Velho da Costa e o absurdo

história de um menino que aprende a crescer e a continuar a viver enquanto segura no regaço o corpo morto de um gato que o pai acabara de atropelar.

Maina Mendes, por outro lado, é um romance pródigo em epígrafes, pelo menos uma por capítulo. Aparecem em português, espanhol, francês, inglês e alemão. As epígrafes de Maria Velho da Costa são uma forma de a romancista prestar homenagem aos autores e obras, canónicas e não-canónicas, que reivindicam a sua preferência em determinado momento; mas são também o modo como a autora vai construindo a sua constelação-de-poetas. Vou deter-me um pouco sobre as epígrafes de Maina Mendes em língua inglesa, de trás para diante. A mais recente citação usada em último lugar é retirada de "Fixing a Hole", de John Lennon e Paul McCartney do álbum Beatles Sgt. Pepper's Lonely Hearts Club Band, de 1967 (Costa 1969: 205). Algumas páginas antes (idem: 191), Maria Velho da Costa recorre a um passo breve de The Waves, de Virginia Woolf (1931). Na página 149, a epígrafe é retirada de King Lear, de Shakespeare, um diálogo entre Lear e o bobo que tem muito de doloroso nonsense-com-sentido. A segunda epígrafe do romance é um passo de "Carthon", um dos poemas de The Poems of Ossian, inventados por James MacPherson no século XVIII. Anos mais tarde, em O livro do meio, escrito de co-autoria com Armando Silva Carvalho, Maria Velho da Costa recorda nostalgicamente uma certa D. Maina Mendes de Sousa que foi um dos pilares da sua infância. ${ }^{14}$ Seja como for, deve ter sido com enorme prazer que a autora descobriu em "Carthon" Moina, a bela esposa de um guerreiro gaélico e mãe do seu filho, três membros trágicos de uma família tragicamente condenada (cf. MacPherson 1996: 127-137 [128]). ${ }^{15}$ Hoje como ontem, nós como eles - a autora insinua - a vida nunca foi fácil de viver, e as famílias nem sempre ajudaram, como sugere o quadro de Paula Rego intitulado "The Family" ${ }^{16}$ As complexidades de famílias multiculturais e poliglotas podem também estar por detrás do nome que o mestiço Orlando, em Irene ou o contrato social, dá à sua cadela, presente do seu padrasto judeu-alemão: Maina, que surgiu do possessivo alemão meine [minha], Orlando aprenderá mais tarde, é também o nome de um livro cheio de infortúnios (Costa 2000: 168; 189).

Tenho vindo a sugerir que Maria Velho da Costa é uma escritora cosmopolita. Tudo o que escreve surge intertextualmente rico de referências a obras de imaginação literária. Literatura e cultura portuguesas, acima de tudo, sem excluir a sua própria ficção (auto-intertextualidade, pois), como temos visto, mas de modo nenhum exclusivamente. São, no entanto, de sublinhar as suas afinidades com a cultura inglesa. A autora é licenciada em Inglês e Alemão pela Universidade de Lisboa, nos anos sessenta do século passado foi professora de inglês no ensino secundário em Portugal, e foi leitora de português no King's College London na década de 1980. Durante os primeiros anos em Londres, Maria Velho da Costa escreveu uma série de crónicas para o diário A Capital. ${ }^{17}$ Uma desses crónicas, sobre o romance Square Tolstoi de Nuno Bragança (1981), ${ }^{18}$ começa por citar a Alice de Lewis Carroll no já mencionado VIII capítulo de Through the Looking Glass. Vejamos primeiro o título da crónica: "Square Tolstoi, Gordon Square, Eighth Square." Square Tolstoi é uma praça em honra de Tolstoi em Paris, a cidade onde Nuno Bragança viveu, amou, trabalhou, escreveu romances e conspirou contra a ditadura de Salazar na década de 1970. A praça surge proeminente no final do romance de Bragança, 
quando um protagonista muito bêbado e muito parecido com Bragança re-imagina as suas muitas aspirações, desejos e frustrações invocando um sem número de autores subversivos, tais como Henry Miller, Albert Camus, André Breton, José Bergamin, e o próprio Tolstoi, para terminar perguntando-se melancolicamente: "Mas escrever porquê?" (Bragança 2009: 409583 [579-581]). Gordon Square, um jardim em Bloomsbury, Londres, não pode deixar de evocar as referências literárias de Bloomsbury. Na sua crónica, Maria Velho da Costa chega a imaginar Virginia Woolf no jardim, a passear, a fumar, a falar sozinha, a criar. Por último, Eighth Square é, podíamos dizer, invenção de Maria Velho da Costa: diz respeito ao VIII capítulo de Through the Looking Glass, que tem por título "It's My Own Invention", e não é senão um lugar imaginativo de reverberações poéticas e mágicas.

O VIII capítulo de Through the Looking Glass conta como Alice foi atacada pelo Cavaleiro Vermelho e salva pelo Cavaleiro Branco. É mais que cómica a paródia hilariante do código de cavalaria quando um disparatado cavaleiro bom vem galantemente em socorro de uma donzela atacada por um cavaleiro mau, igualmente disparatado. Logo que o Cavaleiro Vermelho desaparece, porém, a ridícula narrativa mostra nuances de meiguice e ternura. O Cavaleiro Branco leva Alice até ao extremo do bosque enquanto ambos trocam agradavelmente impressões, por mais risíveis e absurdas. O patético Cavaleiro Branco continua a cair do seu patético cavalo, arrastando consigo a tralha toda que traz consigo, mas Alice está lá sempre para o ajudar. Ele insiste em contar-lhe todas as suas invenções disparatadas, e ela lá está para responder com todo o carinho. A pouco e pouco, a cena torna-se cada vez mais comovente, à medida que se aproxima o momento de dizer adeus. Não é difícil de imaginar Lewis Carroll (que é também o cientista e inventor Charles L. Dodgson) despedindo-se da sua muito querida Alice Pleasance Liddell. ${ }^{19} \mathrm{O}$ passo que Maria Velho da Costa escolheu para iniciar a sua crónica reproduz os pensamentos de Alice (porventura em tradução da própria autora) ao ver o Cavaleiro Branco a desaparecer desajeitadamente na floresta e a cair uma vez mais:

Alice disse para si própria, a vê-lo ir. Lá vai ele! Mesmo de cabeça, como de costume. De qualquer das maneiras lá vai andando bastante bem - é de ter tanta tralha pendurada à volta do cavalo. ${ }^{20}$

"Square Tolstoi, Gordon Square, Eighth Square" é um texto ostensivamente sobre Square Tolstoi. O romance de Nuno Bragança é mencionado no título, evidentemente, bem como na última linha do primeiro parágrafo, logo a seguir a Maria Velho da Costa ter escrito que se sentia tão feliz como Alice no fim da Sétima Casa. Quer ela dizer o VII capítulo de Alice's Adventures in Wonderland, quando uma minúscula Alice consegue finalmente crescer o suficiente para chegar ao belíssimo jardim. Maria Velho da Costa, por sua vez, sente-se feliz porque lhe deu prazer ler o novo romance do seu amigo, Nuno Bragança. Mas o que verdadeiramente me fascina é o modo subtil como Maria Velho da Costa articula Alice na sua resposta, um tanto crítica, não só com o romance de Nuno Bragança, mas também com o próprio autor enquanto homem sedutor de muitas aventuras e ainda mais desaventuras ("Tudo, tudo é autobiográfico", comenta ela, [Costa 1984: 141]). ${ }^{21}$ Há, em primeiro lugar, a referência 
Cadernos de Literatura Comparada

Eukié: Maria Velho da Costa e o absurdo

ao jardim (ou jardins). A Alice estava feliz porque tinha conseguido finalmente chegar ao jardim. Maria Velho da Costa, por sua vez, não conseguindo chegar ao Gordon Square, onde sempre costumava ir nesse dia da semana, teve de contentar-se com passear pelo jardim. E é isso que faz - na página e meia seguinte desta crónica, que não tem mais de quatro páginas e meia ao todo. A memória do fim trágico de Virginia Woolf trá-la de novo à realidade, mas não sem associar a romancista inglesa com a Oitava Casa e com uma rainha que se foi (no final do VIII Capítulo de Alice's Adventures in Wonderland, a Rainha de Copas de facto foi-se embora). É então que Maria Velho da Costa percebe que tem de lembrar aos seus leitores (quem sabe se não lembrar-se a si própria) que o texto de que se ocupa debruça-se, sem dúvida, sobre Square Tolstoi, bem como sobre o seu colega-romancista e muito querido amigo, Nuno Bragança. Nas duas páginas que restam, Maria Velho da Costa escreve sobre Square Tolstoi, virando do avesso, por assim dizer, o romance e o seu autor. É com grande perícia que ela recolhe das obras de Nuno Bragança palavras, sensações, sentimentos; invoca figuras, cenas e diálogos; re-imagina contextos e consequências. Tudo isto para traçar o retrato solitário de um escritor a lutar (como ela própria) com o exílio, a língua no exílio e ele próprio como um homem carregando um pesado fardo, ou, tal como o Cavaleiro Branco de Alice, um homem com demasiada tralha ["too many things"]. Como não voltar ao incipit da crónica, em que se mostra Alice a observar o Cavaleiro Branco, afobado com toda a sua tralha, a cair de novo e de novo a erguer-se uma última vez? Estou tentada a especular que o Cavaleiro Branco se apresenta a Maria Velho da Costa como a perfeita figura do novelista que escreveu um romance intitulado Directa (1977), que em inglês se diz an all-nighter - ou white night [noite branca, com o cavaleiro (knight) a reverberar na noite]. Ao sentidamente escrever sobre Nuno Bragança, Maria Velho da Costa não pode deixar de pensar em si. No início deste artigo, citei um passo desta crónica: "Como se fôssemos nós que nos escrevêssemos". Não somos, continua ela, só nos escrevemos uns aos outros. Ter-lhe-á ocorrido que alguns parágrafos de Maina Mendes enchem de felicidade o autor/protagonista de Square Tolstoi? ${ }^{22}$ O que nós somos, conclui ela, não é mais do que tralha pendurada no cavalo. $\mathrm{O}$ autor de ficção não passa de um actor do paradoxo de escrever enquanto inter-e-intra-promiscuidade-textual. ${ }^{23}$ À pergunta- "Para quê escrever?" - Maria Velho da Costa responderá mais tarde em O livro do meio (Costa 2006: 161), tendo em mente a obra de Bragança e a sua própria: trata-se de uma pergunta disparatada, tal como perguntar para quê respirar.

Em 1983, em Londres, dando aulas em King's College e escrevendo as crónicas de Mapa cor de rosa, Maria Velho da Costa trouxe a lume um novo romance, intitulado Lúcialima, que exibia uma capa extraordinária desenhada por Paula Rego. Não encontramos qualquer referência explícita a Alice neste romance, o qual se constrói de várias histórias independentes que a narradora combina no final. Mas a menina que é protagonista numa das histórias, Lucinha, é inequivocamente uma personagem que lembra a figura da Alice de Carroll. ${ }^{24} \mathrm{Ambas}$ as meninas sofrem uma experiência que as faz perguntarem-se quem são elas afinal. Alice cai acidentalmente pelo buraco do coelho abaixo; Lucinha fica cega aparentemente em consequência de um acidente de viação. Pensando em Lucinha, não há como voltar a Maina Mendes e ver 
esta também como uma figura-de-Alice, até porque Alice, Maina, e Lucinha carecem todas de mãe, de uma forma ou outra. Mas em Lúcialima, um livro povoado de pássaros e animais de toda a espécie, uma cena há que imediatamente nos faz regressar a Alice's Adventures in Wonderland. Lucinha sofre uma estranha alucinação que reflecte a sua ansiedade acerca dos desencontros dos seus pais, cujas constantes quezílias ela não pode deixar de ouvir (Costa 1983: 153-166). Acontece, então, que Lucinha se vê envolvida numa estranha conversa com uma criatura ainda mais estranha sentada em cima de um cogumelo, uma cena que mais parece uma demanda em busca de identidade. Quando Lucinha lhe pergunta quem é ela, a criatura responde, "eu sou eu", o que leva Lucinha a dirigir-se-lhe, muito apropriadamente, recorrendo a uma forma de nonsense lógico, como "Eukié".

Esta conversa entre quem é quem não pode senão trazer de novo à memória Alice's Adventures in Wonderland. No final do IV Capítulo, uma Alice minúscula procura algo que comer ou beber na esperança de recuperar o seu tamanho normal, quando depara com uma lagarta sentada em cima de um cogumelo. No V Capítulo, quando a lagarta lhe pergunta, "Quem és tu?", Alice não sabe o que responder; depois de tantas mudanças de tamanho (ou seja, de identidade), Alice já não sabe quem é realmente. Quando a lagarta lhe pede que a si própria se explique, a resposta de Alice - "Não posso explicar-me a mim própria [...] porque não sou eu própria" - mais parece um comentário proléptico sobre as perplexas angústias de Lucinha sobre si própria e os seus pais. Alice obtém do cogumelo a magia mastigável que a ajudará a controlar o tamanho (ou seja, a sua identidade) e eventualmente a viver uma vida normal no mundo real. Lucinha, cuja cegueira, tal como a mudez de Maina, não é fisiológica, fica-se no reino da fantasia que, só ele, lhe aplaca a ansiedade. Também em Casas Pardas, encontramos uma Mary, obnubilada pelo infortúnio e pelo álcool, "a decrescer, a decrescer" em seu sonho premonitório e a pensar "Sou como a Alice mas não tenho cogumelo para comer" (Costa 1986: 107). Em O livro do meio, a troca de cartas com Armando Silva Carvalho duplamente autobiográfica e, de resto, uma crítica feroz do meio cultural português no início do século XXI, aprendemos que Maria Velho da Costa, ela própria, se vê por vezes como Alice. Na carta datada de 1 de Março de 2006, escreve ela que "A Rapariga Velha" [Velha? Como em Velho da Costa?] se sente feliz na sua casinha, mesmo se de vez em quando se divirta a dizer algo que não é bem verdade: "que se sente como a Alice de Carroll, quando toma a poção que a faz enorme e sair-lhe o corpo pelas aberturas da casa, a cabeça pela chaminé, braços e pernas por janelas e porta" (Costa 2006: 41).

Mas pode bem ser que a ligação mais relevante de Maria Velho da Costa com o nonsense-com-sentido de Lewis Carroll esteja em Casa Pardas, onde se diz que "Alice" está muito na moda (Costa 1986: 229). No início do capítulo intitulado "IV/Casa de Elisa/Angelus", a aspirante a escritora, Elisa, ao reflectir sobre a situação em Portugal durante a chamada Primavera Marcelista, apresenta uma curiosa fábula: "Fábula De Rerum Novarum ou A Raposa Europeia" (idem: 292). O título do capítulo deliberadamente coloca num contexto de fábula a encíclica do papa Leão XIII de 15 de Maio de 1891, De rerum novarum, a qual se debru- 
Cadernos de Literatura Comparada

Eukié: Maria Velho da Costa e o absurdo

çava sobre as condições miseráveis das classes trabalhadoras da Europa no final do século XIX. A raposa introduz a fábula; a narrativa da raposa voraz que devorou tanto que se transformou na loba do mito da fundação de Roma (ou Europa) introduz o tema, tão frequente em Maria Velho da Costa, da violência da cultura. Publicado três anos após a Revolução dos Cravos, quando finalmente as condições miseráveis das classes operárias portuguesas começavam realmente a beneficiar da social democracia europeia, o romance (Casas Pardas), lidando com o período imediatamente anterior ao fim da ditadura de Salazar, mostra-se um tudo nada céptico acerca da bondade das instituições europeias. Claramente invocando Alice, a protagonista, Elisa, sente-se tentada a ver os governantes como um mero baralho de cartas (Costa 1986: 293-294). No último capítulo de Alice's Adventures in Wonderland, intitulado "Alice's Evidence", o testemunho de Alice, que entretanto recuperara o tamanho normal, é: "Who cares for you? [...] You're nothing but a pack of cards!" [Quem vos iria dar importância? (...) Não passais de um baralho de cartas].

Missa in Albis é porventura o mais complexo dos romances de Maria Velho da Costa. Jogando com uma variedade alucinante de alusões paródicas e citações não raro deliberadamente incorretas de nomes reais de pessoas, títulos e eventos, Missa in Albis demonstra na perfeição que a grande literatura se escreve na literatura, a grande poesia, na poesia. Narrado por múltiplas vozes muitas vezes difíceis de distinguir, assim confundindo também a leitora sobre onde colocar a verdadeira voz da "autora", se bem que ela esteja lá perfeitamente em todas e em cada uma das personagens, de entre o grupo de amigos que constituem as principais do romance, Missa in Albis é o romance que mais denuncia Maria Velho da Costa como leitora e que mais exibe ricos jogos de palavras e situações e relações deliberadamente tornadas absurdas e paradoxais, muitas vezes a partir de textos do cânone ocidental. A escrita tecida pela romancista, porém, coincide rigorosamente com o tecido da nação na primeira década da segunda metade do século XX até à Revolução dos Cravos e um pouco depois dela. O romance denuncia taras e crimes de indivíduos e famílias que vão reflectindo o estado da nação. "Tudo é autobiográfico", vimos Maria Velho da Costa reconhecer na sua crónica sobre Square Tolstoi de Nuno Bragança. Não cito de novo este reconhecimento da romancista para encorajar que se procure a própria autora nos seus romances, tarefa fútil do ponto de vista da literatura e da poesia: uma vez incluída na narrativa ficcional, que é como quem diz no poema, a vida passa logo a ser ficção. O mesmo se diga da religião, como nos ensinam as epígrafes de Missa in Albis, todas elas refeitas (ou ficcionadas) a partir da Missa Tridentina; na da página 419, "Memento etiam, Domine", esta leitora julga encontrar "Ruy" Belo, morto em 1978, e "Nuno" Bragança, falecido em 1983.

Mas voltemos ainda a nossa atenção para uma "Alice" que inopinadamente surge em Missa in Albis, trazendo consigo o gato de Cheshire, uma inequívoca alusão à discussão absurda sobre a loucura ou sanidade de cães e gatos no VI Capítulo de Alice's Adventures in Wonderland ("Pig and Pepper") (Carroll 1976: 357, 358, 361) e outra às transformações físicas, ou de identidade, de Alice (idem: 412). E como entender a Elisa de Maria Velho da Costa em Casas Pardas? Elisa, cujo nome é quase um anagrama de Alice, e cuja invocação de "A Mad Tea Par- 
ty" a encorajou a entrar numa sucessão de "casas", não "pardas", mas "parvas" (Costa 1986: 294). Temos aqui o melhor do nonsense carrolliano abraçado por Maria Velho da Costa em toda a sua obra. Como diz uma das autoras (não identificada[?]) de Novas cartas portuguesas, a Alice vai crescendo "de volume em volume" (Barreno/Horta/Costa 2010: 98). ${ }^{25}$

Temos de concluir que a Alice de Lewis Carroll desempenhou um papel importante na construção da imaginação poética de Maria Velho da Costa. Em The Story of Alice de Robert Douglas-Fairhurst, aprendemos que Lewis Carroll usou o nonsense e o absurdo obliquamente, por vezes talvez sem se dar conta, para pintar as contradições da sociedade vitoriana, como se de uma fábula se tratasse. ${ }^{26}$ Maria Velho da Costa, por sua vez, usa deliberadamente o nonsense e o absurdo, jogando com as sonoridades desconcertantes da língua (ou das línguas), para denunciar as gritantes e injustas desigualdades da sociedade portuguesa, ao mesmo tempo que caricatura implacavelmente as persistentes pretensões e o potencial para a corrupção das classes dirigentes, no Portugal de antes e depois do 25 de Abril.

*

P.S. Não será por acaso que se ouve por vezes dizer que os romances de Maria Velho da Costa parecem escritos em língua estrangeira, tal o seu jogo de sentidos e de sem-sentidos-com-sentido. Marcel Proust escreveu um dia: "Les beaux livres sont écrits dans une sorte de langue étrangère. Sous chaque mot chacun de nous met son sens ou du moins son image qui est souvent un contresens. Mais dans les beaux livres, tous les contresens qu'on fait sont beaux" (Proust 1954: 361). ${ }^{27}$ Por alguma razão, a primeira destas frases de Proust ("Os livros belos são escritos numa espécie de língua estrangeira") serve de epígrafe a Critique et clinique, de Gilles Deleuze, cuja obra, em geral, tão útil me tem sido para ler Maria Velho da Costa. De resto, há muito já que também eu venho dizendo que a língua da poesia é sempre a mesma, e sempre uma língua estrangeira. Nada mais oportuno que um belo poema, de um grande poeta, a antecipar-se à pretensão teórica da leitora.




A leitora não pode senão servir-se de "palavras já formadas"; a poesia descobre-lhes o "nascimento vibrante". Não disse Rimbaud que a poesia vai sempre à frente? ${ }^{28}$

NB: Maria Irene Ramalho não aceita o novo acordo ortográfico!

\section{NOTAS}

* Maria Irene Ramalho é professora jubilada da Faculdade de Letras e investigadora principal do Centro de Estudos Sociais (Universidade de Coimbra). De 1999 a 2018 foi International Affiliate de Department of Comparative Literature (University of Wisconsin-Madison). É autora de Atlantic Poets (2003; ed. br. 2007, ed. pt. 2008) e "Poetry in the Machine Age" (The Cambridge History of American Literature, vol. V, 2003). Co-org. (com Mario Materassi), The American Columbiad (1996), (com António Sousa Ribeiro), Translocal Modernisms (2008), (com Doris Friedensohn), Transnational, Post Imperialist American Studies? (2010), (com Adriana Bebiano), Estudos Feministas e Cidadania Plena (2010) e (com Isabel Caldeira e Maria José Canelo), America Where? (2012). É organizadora de 6 volumes de Poesia do Mundo (1995, 1998, 2001, 2004, 2007 e 2010). Os seus trabalhos mais recentes incluem "Poetry in America" (2012), "Difference and Hierarchy Re-visited by Feminism" (2013), "Quando o lírico interrompe o épico. Sobre Escuro de Ana Luísa Amaral" (2014), "Blindfolded Eyes and the Eyable Being. Pessoa, the Senses, and the 35 Sonnets" (2016), "A humana condisoooooooooong. Sobre De novo falo, a meia voz de Alberto Pimenta" (1916), "Diferença? Ou variedade infinita" (1916), "Orpheu et al. Modernism, Women, and the War" (2017), "Europe and America. An Age-Old Relationship Revisited" (2017), "Coisas. A propósito de What's in a name? de Ana Luísa Amaral” (2017), "What the Poet Meant. Teaching Wallace Stevens to Portuguese Students" (2017), "The Private is Public or Furbies Are Us" (2017), (com Adriana Bebiano) "A Revista Crítica de Ciências Sociais e o Feminismo" (2018), "Um caminho curto para um poema grande". Sobre Pensar depois/no caminho de Alberto Pimenta (2019), "Zombo: A musa incansável de Alberto Pimenta" (2019) e “'E o que era ser são?' Intersexualidades e vidas vivíveis” (2019).

${ }^{1}$ Uma versão ligeiramente diferente deste ensaio foi publicada, em língua inglesa, em Portuguese Studies 35.2 (2019) 216 -227. Tudo começou na Transnational Women Artists Conference (Wadham College, Oxford, Março de 2017), da responsabilidade de Claudia Pazos Alonso, a quem agradeço ter-me convidado a proferir a conferência plenária do congresso.

${ }^{2}$ Tiago Bartolomeu Costa, "Entrevista a Maria Velho da Costa. Uma flor no deserto". Público, 13 de Janeiro de 2013. Ver também Luís Miguel Queiroz, "Prémio da APE a Maria Velho da Costa consagra uma obra que revolucionou a ficção portuguesa". Público (Ipsilon), 2 de Dezembro de 2013.

3 Veja-se a introdução de Woollcott em Carroll 1976: 5. Sem indicação em contrário, todas as traduções são minhas.

${ }^{4}$ Cap. X, “The Lobster Quadrille”, The Complete Works: 112. 
${ }^{5}$ M. Irene Ramalho Santos, "Gender, Species and Coloniality in Maria Velho da Costa." Em Gender, Empire, and Postcolony: Luso-Afro-Brazilian Intersections. Ed. H. Owen and A. Klobucka (New York: Palgrave Macmillan, 2014) 191-201; uma versão ligeiramente alargada em língua portuguesa: Maria Irene Ramalho, "A violência da cultura. Sexo, espécie e colonialidade em Maria Velho da Costa". Em Representações da violência. Org. António Sousa Ribeiro (Coimbra: Almedina, 2013) 51-63.

${ }^{6}$ Quando lhe perguntam o que está a escrever, uma personagem do romance que é escritora responde: "a história de uma menina que se faz muda para não ser incomodada".

${ }^{7}$ As outras "moralidades" da Duquesa são todas deturpações paródicas de conhecidos provérbios ingleses.

${ }^{8}$ A melhor homenagem é descobrir os trocadilhos no próprio nome do bardo: a (milk)shake é um batido, to shake, gorjear ou dançar (rock \& roll), the shakes, coloquial para delirium tremens, etc.... Curiosamente, existe hoje, mas provavelmente não no tempo que nos interessaria, uma banda inglesa chamada The Shakes.

${ }_{9}^{9}$ Para o poema como segunda natureza ou heterocosmo, ver Abrams 1971: 35; 327.

${ }^{10}$ Veja-se a "Entrevista a Maria Velho da Costa. Uma flor no deserto". Maria Velho da Costa confessa que nunca escreveu poesia e que descartou todas as suas tentativas juvenis com o género. Creio, porém, que o que ela quer realmente dizer é que nunca escreveu em verso.

${ }^{11}$ Curiosamente, em "Declinação", a última "Casa de Mary", a alusão a outro poema de Blake ("O rose thou art sick") merece nota de rodapé. Casas Pardas: 409.

${ }^{12}$ Arnaldo Saraiva, Luísa Costa Gomes, and Beatriz Weigart, entre outros, têm comentado o uso que Maria Velho da Costa faz das epígrafes. Cf. Saraiva 1980: 117-122; cf. Gomes, "A Maina volta a atacar", Ler, n. 23: 51-59; cf. Weigert, "Maria Velho da Costa em Missa in albis", Scripta, 7.13 (2003): 35-54.

${ }^{13} \mathrm{Cf}$. Kane 1961: 104. A relevância deste romance sobre o colonialismo e as relações de poder entre culturas europeias e africanas para Maria Velho da Costa, escritora e cidadã inequivocamente empenhada, é reafirmada pelo menos mais duas vezes nos romances da autora: num passo de Casas Pardas (1977), de que uso aqui a terceira edição, com prefácio de Manuel Gusmão (Costa 1986: 308); e num passo ainda mais marcante de Myra (2008): "Como pudemos perder para quem não tem razão? Pensou Myra, que tinha lido isto num dos livros de Rolando [...] L'aventure ambiguë, de um Sheik preto, Amidou Kane".

${ }_{14}$ Ver também as seguintes páginas: 135, 158, 175, 271, 316, 383, 403.

${ }^{15}$ Tanto quanto sei, Estela Couto Berger foi até à data a única leitora de Maina Mendes que prestou atenção à epígrafe retirada de Ossian. Certamente porque achou importante o patriarcado e as relações de família em Maria Velho da Costa (vide Berger 1998: 96).

${ }^{16}$ Para uma análise interessante de um "diálogo intersemiótico" entre Myra e a poética visual de Paula Rego "visual poetics," ver Macedo 2017, II: 54-71.

${ }^{17}$ As crónicas foram coligidas em 0 mapa cor de rosa.

${ }^{18}$ Para uma breve recensão crítica do romance de Nuno Bragança, assinada por Maria Irene Ramalho de Sousa Santos, ver World Literature Today (Winter, 1983).

${ }^{19}$ Ver o ensaio eloquente de Donald Rackin sobre esta cena: “'And here I must leave you': Death, Love, and the White Knight's Farewell." in Rackin (1991: 127-152).

${ }^{20} \mathrm{O}$ original diz: "['It won't take long to see him off, I expect',] Alice said to herself, as she stood watching him. 'There he goes! Right on his head as usual! However, he gets on again pretty easily - and that comes from having so many things hung round the horse - '" (Carroll 1976: 248).

${ }^{21}$ Quão autobiográfico tudo é, aprendemos no coscuvilheiro "livro do meio" que Maria Velho da Costa co-escreveu vinte anos mais tarde com Armando Silva Carvalho. 
Cadernos de Literatura Comparada

Eukié: Maria Velho da Costa e o absurdo

22 “... fui relaxar o corpo num banho de tina e saboreando alguns parágrafos de Maina Mendes. Experimentava uma felicidade imensa por ter encontrado e haver escrita, e lugar nesta para mim" (Bragança 2009: 550).

${ }^{23}$ A escritora enquanto actriz é tema de análise em Maria José Carneiro Dias, Maria Velho da Costa. Uma poética de au(c)toria. Tese de doutoramento. Universidade do Porto, 2013. Dias chama a atenção para as complexidades da (auto)intertextualidade da ficção Maria Velho da Costa (esp. 166ff). A Imprensa Nacional-Casa da Moeda publicou a tese de Maria José Dias em 2018. ${ }^{24}$ Para uma astuta leitura do título do romance como articulando os nomes das duas personagens mais marcantes - Lúcia, a Menina, e Lima, o homem-fazedor-da-Revolução - ver Berger 1998: 122.

${ }^{25}$ A citação completa: "a rainha do baralho de cartas (todas lemos, quando lemos), disse a Alice, 'cortem-lhe a cabeça'. Coisa que muito fez Alice aumentar de volume em volume."

${ }^{26}$ Para um estudo muito esclarecedor dos Livros de Alice no contexto da sociedade victoriana perturbada por Darwin e pelo seu The Origin of the Species (1859), ver Douglas-Fairhurst (2015), esp. o capítulo 12.

${ }_{27}^{2}$ [Os livros belos são escritos numa espécie de língua estrangeira. A cada palavra cada um de nós dá o seu sentido, ou pelo menos a sua imagem, que é muitas vezes um sem-sentido. Mas nos livros belos são belos todos os sem-sentidos].

${ }^{28}$ Carta a Paul Demeny, 15 de Maio de 1871.

\section{Bibliografia}

Abrams, Meyer Howard (1971), The Mirror and the Lamp. Romantic Theory and the Critical Tradition, New York, Oxford University Press.

Barreno, Maria Isabel/ Horta, Maria Teresa/ Costa, Maria Velho (2010), Novas cartas portuguesas, edição anotada, org. Ana Luísa Amaral, Lisboa, Dom Quixote.

Berger, Estela Couto (1998), A audácia da diferença. Percursos femininos na ficção de Maria Velho da Costa, Faro, Universidade do Algarve.

Bragança, Nuno (2009), Obra Completa, Lisboa, Dom Quixote.

Carroll, Lewis (1976), The Complete Works, intro. Alexander Woollcott, New York, Vintage Books.

Carvalho, Armando Silva/ Costa, Maria Velho da (2006), O livro do meio, Lisboa, Caminho. Costa, Maria Velho da (1966), O lugar comum, Lisboa, Moraes.

- (1969), Maina Mendes, Lisboa, Moraes.

- - (1976), Cravo, Lisboa, Moares.

- - (1986), Casas Pardas, Lisboa, Dom Quixote [1977].

- (1983), Lúcialima, Lisboa, O Jornal.

-- (1984), O mapa cor de rosa. Desenhos de Oscar Zarate, Lisboa, Dom Quixote. 
- - (1988), Missa in albis, Lisboa, Dom Quixote.

-- (2000), Irene ou o contrato social, Lisboa, Dom Quixote.

Costa, Tiago Bartolomeu (2013), "Entrevista a Maria Velho da Costa. Uma flor no deserto". Público, 13 de Janeiro de 2013.

Deleuze, Gilles (1969), Logique du sens, Paris, Minuit.

-- (1993), Critique et clinique, Paris, Éditions de Minuit.

Dias, Maria José Carneiro (2013), Maria Velho da Costa: Uma poética de au(c)toria, tese de doutoramento, Universidade do Porto. [(2018),Porto, Imprensa Nacional-Casa da Moeda].

Douglas-Fairhurst, Robert (2015), The Story of Alice. Lewis Carroll and the Secret History of Wonderland, London, Harville Secker.

Kane, Cheikh Hamidou (1961), L'aventure ambiguë, Paris, Julliard.

Macedo, Ana Gabriela (2017), "Material Culture, New Corpographies of the Feminine and Narratives of Dissent. Myra, by Maria Velho da Costa and Paula Rego - an Intersemiotic Dialogue", in The Edge of One of Many Circles. Homenagem a Irene Ramalho Santos, ed. Isabel Caldeira, Jacinta Matos and Graça Capinha, Coimbra, Imprensa Nacional da Universidade de Coimbra.

MacPherson, James (1996), The Poems of Ossian and Related Works, edited by Howard Gaskill, with an introduction by Fiona Stafford, Edinburgh, Edinburgh University Press.

Proust, Marcel (1954), Contre Sainte-Beuve, Paris, Gallimard.

Queiroz, Luís Miguel (2013), "Prémio da APE a Maria Velho da Costa consagra uma obra que revolucionou a ficção portuguesa", Público (Ipsilon), 2 de Dezembro de 2013.

Rosa, António Ramos (2001), Deambulações oblíquas, Lisboa, Quetzal.

-- (2002), "A leitura de um livro por outro livro e a sua correspondência intertextual", in Rosa Alice Branco, Soletrar o dia: obra poética, V. N. Famalicão, Edições Quasi.

Santos, Maria Irene Ramalho (2013), "A violência da cultura. Sexo, espécie e colonialidade em Maria Velho da Costa", in Representações da violência, org. António Sousa Ribeiro, Coimbra, Almedina.

-- (2014), "Gender, Species and Coloniality in Maria Velho da Costa", in Gender, Empire, and Postcolony: Luso-Afro-Brazilian Intersections, ed. H. Owen and A. Klobucka, New York, Palgrave Macmillan.

Saraiva, Arnaldo (1980), Literatura marginalizada, Porto, Árvore.

Smart, Christopher (1966), Jubilate Agno, ed. W. H. Bond, Westport, CT, Greenwood Press. 